Dr Cindé Greyling

Doctoral graduate

Disaster Management

Training and Education

Centre for Africa,

Faculty of Natural and

Agricultural Sciences,

University of the Free

State, Bloemfontein

cindegreyling@gmail.com

Dr Lydie Terblanche

Department of

Communication Science,

University of the Free

State, Bloemfontein

terblanl@ufs.ac.za

Prof. Andries J Jordaan

Director

Disaster Management

Training and Education

Centre for Africa,

Faculty of Natural and

Agricultural Sciences,

University of the Free

State, Bloemfontein

jordaana@ufs.ac.za

DOl: https://dx.doi.org/

10.18820/24150525/

Comm.v21.6

ISSN 1023-0556 (Print)

ISSN 2415-0525 (Online)

Communitas201621:73-88

(c) UV/UFS

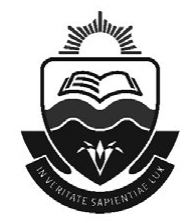

\section{A DROUGHT RISK REDUCTION MESSAGE THAT STICKS: A COMMUNICATION MODEL FOR FOUNDATION PHASE CHILDREN}

\section{ABSTRACT}

Too often, children's communication needs are not considered when it comes to important messages - especially concerning disaster risk reduction. Drought has a significant impact on children both mentally and physically, however, they are rarely told how to make themselves more resilient. Messages aimed at drought resilience are mostly presented in a format that children will not understand, or care to understand. Children have quite unique communication needs with regard to message content, language, media and culture. These needs were researched and moulded into an existing cyclical communication model that may prove to be a useful guideline in constructing a message towards drought resilience for foundation phase children. The main aim of the adapted model is to offer messages containing the "stickiness" factor.

Keywords: drought; disaster; communication; children; resilience; risk reduction; foundation phase

\section{INTRODUCTION}

This article presents a synopsis of an early section in a study developing a narrative communication approach towards drought resilience for foundation phase children. Although the study delivered a number of data sets, the focus will only be on the development of a communication model that guided the development of the drought risk reduction message.

Of all the hazards people face, drought is believed to be the most complex but also the least understood of all natural hazards; it also affects more people than any other natural hazard (Wilhite 1999). In many cases children count among the most vulnerable - destroyed or distraught by the impact of drought and their inability to make themselves more resilient. In order to increase drought resilience, behavioural change is required. To achieve behavioural change, the message must be of such a nature that it "sticks" in children's minds. Considering the complexity of drought, the model (or blueprint) used to create the message must be thoroughly reflected on. Even though academics have studied communication 
for many years, Miller-Day, Pezella and Chesnut (2013) state that only $3,7 \%$ of all published articles in leading communication journals from 1997 to 2010 focused on children. The authors point out that this is much less than the $10 \%$ estimated in previous research. Although this study focused on South African children, the message creation can be universally applied. Part of the initial process of the study was to construct a model according to which the message could be developed - the construction of this model is summarised here.

\section{Methodology}

Firstly, the most suitable communication model was sought. Thereafter the specific communication needs of foundation phase children were researched in order to arrive at the best possible model to be used in creating a message towards drought resilience. Therefore, existing literature and secondary data was used to arrive at the conclusions made. According to Patton (2001: 226), a literature review answers the question of what is already known. What is known can then be adapted to suit different circumstances.

Once the model was constructed, a message was developed according to the guidelines of the model. The message "stickiness" was tested by participant observation to record the children's response to the developed material. According to Jorgensen (1989: 12), participant observation - where direct observation is the primary method of data gathering and can be conducted by a single researcher - can be used for almost any study regarding human existence and is appropriate to critically examine claims to knowledge. Observation allows the researcher to collect live data that can potentially be more valid than second-hand accounts (Cohen, Manion \& Morrison 2007: 398).

Since data could not be collected for the entire population, typical case sampling was used. There was no need for the testing to deliver representative results. The secondary data that guided the development of the communication model was representative in itself. The testing was merely used as a method of triangulation and illustrative of the outcomes of the secondary data.

\section{REDUCING DROUGHT RISK FOR CHILDREN}

For any risk reduction initiative to be effective, Shaw et al. (2004: 42) emphasise that five stages should be involved: knowing, realising, deepening, decision and action. These stages lay a heavy burden on any risk reduction effort. It requires that the process by which children receive information, process it and act on it, needs to be understood. Using the Rohrman awareness model (1998) with its three levels of risk appraisal, decision for prevention, and risk reduction, Shiwaku et al. (2007: 580) propose an educational framework that enhances awareness and promotes action for disaster reduction, community education, family education and school education. This framework emphasises that whatever is taught should not be for the sake of providing information only. The experience should specifically enable children to identify risks and hazards in their environment, assist them in making conscious decisions and teach them to take action to prevent the risks, and ultimately support displaying risk-reducing 
behaviour. These goals could be achieved through generating curiosity about hazards and disasters by using an effective communication process (Rambau 2011: 50). This means that the communication process by which children are involved in risk reduction needs to be entertaining, imaginative and educational at the same time in order to change consciousness and behaviour. Besides the need to be entertaining, imaginative and educational, the success of such a communication process is further challenged by the fact that today there are higher levels of multiculturalism as more and more people migrate to locations outside their culture zones where languages, perceptions and attitudes towards disaster differ (Clerveaux, Spence \& Katada 2010: 202).

\section{Framework for a drought risk reduction communication model}

The most basic communication model was developed by Shannon in 1948. It is still taught to communication students today, which could be viewed as testament to its enduring value (Foulger 2004a). Shannon's simple linear model consists of five parts, as elaborated by Blackburn (2007: 60) as follows:

- information source producing the message

- transmitter encoding the message

- channel through which the message is sent

- receiver decoding the message

- destination referring to the person for whom the message is intended

FIGURE 1: SHANNON AND WEAVER'S MODEL OF COMMUNICATION

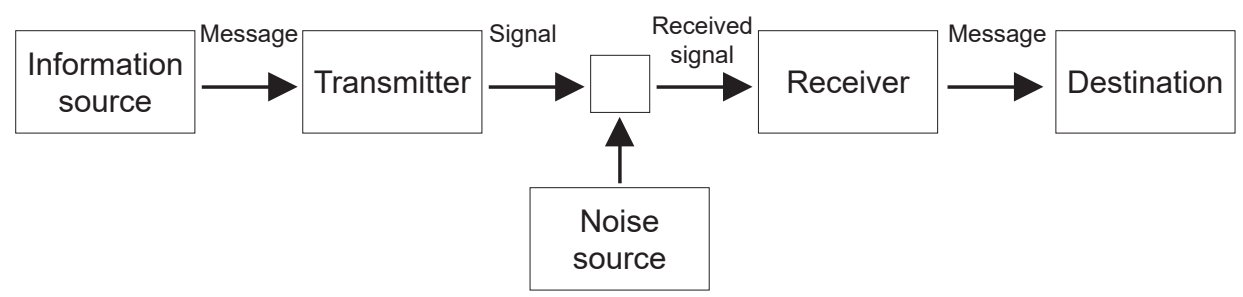

(Source: Corman, Trethewey \& Goodall 2007: 3)

When this model was initially developed, Shannon had the telephone or telegraph in mind. Since then, much has changed in the communication arena. This rapid development is discussed at length by Holmes (2005), referring to the current "second media age" that describes cyber communication and the advance in electronic and wireless communication. Littlejohn and Foss (2009) present a chronological development of communication theories from the Classical Period until 2008. The development of the field of communication is closely related to social developments through time, ranging from multi-cultural theories, feminism, the rise of interpersonal communication theories and an interest in the non-verbal aspects of communication to mass media and advanced technological theories. However, Miller (1996) states that some aspects of both written and oral communication have remained unchanged. 
She argues that "communication is still the social glue that holds together nations, corporations, scientific disciplines and families".

Figueroa et al. (2002) share Miller's sentiment in defending the validity of different types of communication models by arguing that no theory is right or wrong, it is only appropriate or inappropriate - depending on the environment and situation in which it is applied. A model like, for example, Shannon's five-step linear model, was too simplistic and speculative to apply in the study discussed in this article, thus rendering such approaches inappropriate. One reason is that linear models lacks what Berlo (1960, in Corman et al. 2007: 4) calls fidelity - which describes the effect of the message. Linear models also assume that the receiver will indeed receive the message and that they will understand it. Although the effect of noise (that can interfere with the message clarity) is included in most linear models, the general assumptions of such models were too generous for the purposes of the study under discussion.

Since the rise of linear communication models, many other models have been created by various scientists to suit their specific area of communication (e.g. marketing, public relations, advertising, politics) with the aim of including factors that were not applicable in typical linear models like Shannon's, such as feedback, language barriers, gatekeepers, culture, perception and different types of media. Some of these models include Schramm's (1957) face-to-face model; Berlo's (1960) SenderMessage-Channel-Receiver (SMCR) model and Barnlund's (1970) more complex transactional model accounting for the continuous, unrepeatable, irreversible nature of communication (Littlejohn \& Foss 2009).

Miller (1996: 3), however, warns against over-simplifying communication as packaging messages and transmitting them. Such an approach denies the complex interaction of knowledge, language, habit, presumptions, values and interests that all affect the communication process. Communication should rather be thought of as an art. Accordingly, a good starting point among the available models for the current article was to analyse Foulger's (2004b) ecological model of the communication process. Foulger (2004b) attempted to address the gaps in other communication models by:

i. assigning an active role to the receiver of the message;

ii. allowing for different interpretations of the message;

iii. recognising the different types of language use in different media;

iv. proposing that receivers learn about the media by using the media;

v. noting that the creators of the message actually invent and evolve language; and

vi. that the messages constructed can in fact be imperfect representations of the meaning actually imagined.

He argues that the roles of the message creators and message consumers are both reflective and introspective in that people create messages in reaction to other people's messages, and that the interpretation of the messages is influenced by each person's own perspective. 


\section{FIGURE 2 : ECOLOGICAL MODEL OF THE COMMUNICATION PROCESS}

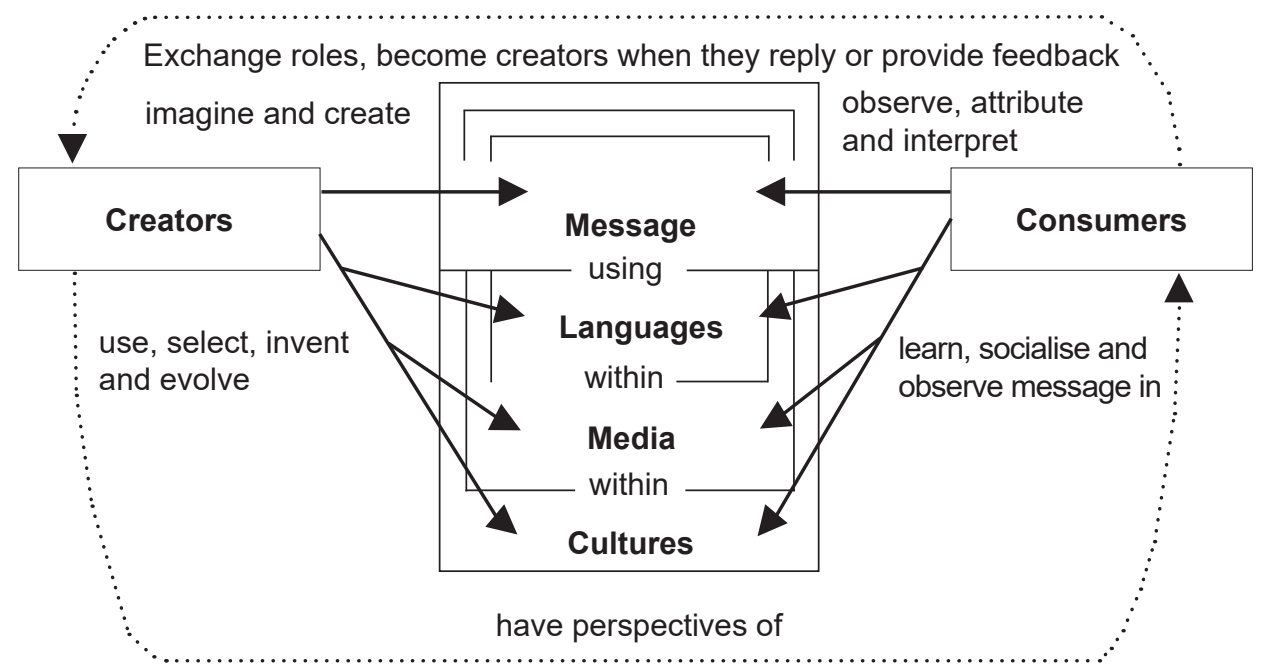

(Source: Foulger 2004b)

Simply put, the ecological model of the communication process assigns an equally important role to the sender and the receiver of any message to aid the success of the message.

\section{Drought risk reduction message characteristics}

According to Foulger's (2004b) model, message creation by the creator lies at the core of the communication process. Firstly, the sender must have a very clear idea of the message to be sent, and secondly, the sender must have a good understanding of how to create the message in the most effective way. Messages that are unique and rather point out "do's" than "don'ts" prove to be more effective for young children (UNICEF 2006: 14). Kolucki, Iskanderova and Grover (2006: 2) also advise that less is more and simple is best.

A message needs to be noticed to establish a connection through which the communication can be sent before it can be understood. Kirkorian, Wartella and Anderson (2008: 51) found that young children do not understand messages they do not pay attention to, and that they cannot learn from content they do not understand. These authors also assert that repetition is valuable to ensure that the message sticks in the children's minds - be it by means of repeated exposure to the message or by repeating the same message in a variety of ways.

Gladwell (2013: 101-118) found exactly the same in his analysis of the children's television programmes Sesame Street and Blue's Clues. The moment children could not make sense of what they were looking at, they looked away. As soon as the children perceived something as confusing, including too much action, puns and complicated wordplay, they lost interest. The same study also found that repetition is valuable, as well as the integration of reality and fantasy. Although psychologists 
advised the producers of Sesame Street not to fuse reality and fantasy in order to avoid misleading the children, the opposite happened: The moment that fantasy and reality were separated, the children lost interest. However, as soon as the fantasy characters and the adults engaged, interest levels would rise again. The same proved true for a narrative approach - children did not pay much attention to, understand or remember information presented in a non-narrative manner.

Fisch (2000, in Kirkorian et al. 2008: 51) agrees by suggesting that narrative and educational content should be integrated as much as possible. Hamilton and Weiss (2005: 1-11) explain this notion by reasoning that stories are at the core of all the aspects that make us human and that it is the oldest form of education. They argue that children are born with an innate ability to make sense of their world by means of stories and that stories are the way by which the brain stores information.

The above suggests that the message towards drought resilience for foundation phase children should be simple, repetitive, narrative and imaginative and should focus on the positive actions needed in order to reduce drought risk as illustrated in Figure 3.

FIGURE 3: PARTIAL COMMUNICATION MODEL TOWARDS STICKINESS: THE MESSAGE

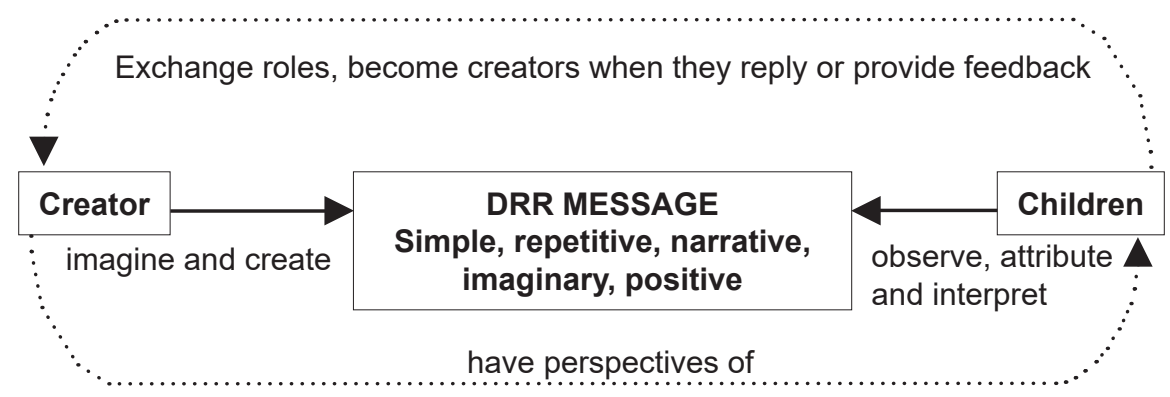

(Source: adapted from Foulger 2004b)

\section{Language characteristics of a drought risk reduction message}

The message content must be converted into a language that foundation phase children will understand. Children face numerous challenges with regard to languages other than their mother tongue (Jongejan, Verhoeven \& Siegel 2007). Therefore, the ideal would be to convey the message in the mother tongue, especially to young children who have not yet, or only partially, acquired the skill of understanding a second language.

According to Pretorius and Machet (2004: 45), the ability to read entails more than just being able to recognise letters and decode words; it also refers to the ability to understand whatever was written. In order to arrive at this understanding, children are required to simultaneously process, retain and retrieve information. This makes a considerable demand on their working memory - a memory system assumingly involved in the active processing of current information (Jongejan et al. 2007: 837). 
The successful processing by the working memory, or the way in which children make sense of language, depends on various aspects, as explained below:

- Orthographic awareness. Orthographic awareness refers to the child's ability to know in which sequence words are put together to form meaning, that is, spelling and spelling rules (Arab-Moghaddam \& Sénéchal 2001: 141).

- Phonological awareness. Phonological awareness refers to the child's ability to link letters with their corresponding sound and to then combine these sounds into words (ibid.).

- Semantic awareness. Semantics involves understanding what words mean as a whole, and in parts, in sentences and discourse. Skilled reading requires the effective processing and combination of orthographic, phonological and semantic formation (Nakayama, Sears \& Lupker 2010: 477).

- Syntactic awareness. According to Lipka and Siegel (2007: 108), syntactic awareness refers to the child's ability to understand the grammatical structure of a language. All languages have rules that determine how words can be put together to form sentences. Although it can be confusing on the one hand, on the other hand it can help a child make sense of a new, difficult word - provided that the child has a good syntactic awareness.

The above is pivotal to the child's vocabulary, which is dependent on prior knowledge or previous exposure to words used to code or decode meaning (Rvachew \& Bernhardt 2010: 35; Miller \& Keenan 2009: 103). Determining the language or prior knowledge of a child may not be easy to establish without testing their knowledge. However, lists of words, phrases and sentences that foundation phase children should know are available from various national and international sources: Dolch Word List (2014); Fry Words (2010); Perkins (1998) and Rasinski (2003), as well as from the national curriculum (Department of Basic Education 2011) and workbooks (Department of Basic Education 2014a; 2014b).

The learning outcomes of the nationally prescribed curriculum for foundation phase children in South Africa provide one way of estimating the language ability of these children.

As can be derived from these curriculum outcomes, a message aimed at foundation phase children would require a large portion of visual elements. The first two grades depend largely on visual content to support reading development. Madigan (2005: 1) suggests that visual symbols greatly aid understanding where reading or language ability falls short, and that the use of pictures can even help children understand abstract ideas. Although Lester (2006) points out that linguistic theorists do not consider pictures as a language because there is no formal grammar, he argues that words too are collections of symbolic images. All words originate from icons, but have evolved to such an extent that it is no longer possible to connect them with the original pictograms. This underlines Lester's (2006) notion that people understand the world by reading pictures - which is emerging once again in our image-entrenched modern culture. 
TABLE 1: READING SKILLS TO BE TAUGHT IN HOME LANGUAGE GRADES R-3

\begin{tabular}{|c|c|c|c|}
\hline Grade R & Grade 1 & Grade 2 & Grade 3 \\
\hline $\begin{array}{l}\text { Emergent reading skills } \\
\text { - Recognises and points } \\
\text { out common objects in } \\
\text { pictures } \\
\text { - Arranges a set of } \\
\text { pictures in such a way } \\
\text { that they form a story } \\
\text { - Interprets pictures, e.g. } \\
\text { makes up own story and } \\
\text { 'reads' the pictures } \\
\text { - Acts out parts of a story, } \\
\text { song or rhyme } \\
\text { - Holds the book the right } \\
\text { way up and turns pages } \\
\text { correctly } \\
\text { - Pretends to read and } \\
\text { adopts a 'reading voice' } \\
\text { - Recognises own name } \\
\text { and names of some } \\
\text { other children in the } \\
\text { class } \\
\text { - Begins to 'read' high } \\
\text { frequency words seen } \\
\text { in the classroom and } \\
\text { at school, e.g. door, } \\
\text { cupboard) } \\
\text { Shared reading as a } \\
\text { class with teacher } \\
\text { - 'Reads' enlarged texts } \\
\text { such as poems, Big } \\
\text { Books, posters } \\
\text { - Makes links to own } \\
\text { experience when reading } \\
\text { with the teacher } \\
\text { - Describes characters } \\
\text { in stories and gives } \\
\text { opinions } \\
\text { - Predicts what will } \\
\text { happen in a story } \\
\text { through the pictures } \\
\text { - Answers questions } \\
\text { based on the story read } \\
\text { - Draws pictures } \\
\text { capturing main idea of } \\
\text { the stories }\end{array}$ & $\begin{array}{l}\text { Emergent reading skills } \\
\text { - Develops book } \\
\text { handling skills (holding } \\
\text { the book and turning } \\
\text { pages correctly) } \\
\text { - Interprets pictures to } \\
\text { make up own story, i.e. } \\
\text { 'reads' the pictures } \\
\text { - Reads logos, labels } \\
\text { and other words from } \\
\text { environmental print } \\
\text { - Recognises own name } \\
\text { and names of peers } \\
\text { - Reads labels and } \\
\text { captions in the classroom } \\
\text { - Develops basic } \\
\text { concepts of print } \\
\text { including } \\
\text { - Concept of a book } \\
\text { - Concept of words and } \\
\text { letters } \\
\text { - Directionality: Starts } \\
\text { reading at front, ends at } \\
\text { back; read from left to } \\
\text { right and top to bottom of } \\
\text { a page } \\
\text { Shared reading as a } \\
\text { class with teacher } \\
\text { - Reads Big Books or } \\
\text { other enlarged texts } \\
\text { - Uses pictures and the } \\
\text { book cover to predict } \\
\text { what the story is about } \\
\text { - Discusses the story, } \\
\text { identifying the main idea } \\
\text { and characters } \\
\text { - Sequences the events } \\
\text { in the story } \\
\text { - Recognises cause and } \\
\text { effect in a story, e.g. } \\
\text { The girl got into trouble } \\
\text { because she broke a } \\
\text { window } \\
\text { - Gives an opinion on } \\
\text { what was read } \\
\text { - Answers open-ended } \\
\text { questions based on the } \\
\text { passage read } \\
\text { - Interprets information } \\
\text { from posters, pictures } \\
\text { and simple tables, e.g. a } \\
\text { calendar }\end{array}$ & $\begin{array}{l}\text { Shared reading as a } \\
\text { class with teacher } \\
\text { - Reads Big Books or } \\
\text { other enlarged texts (e.g. } \\
\text { fiction and non-fiction } \\
\text { books, poems and } \\
\text { songs) } \\
\text { - Uses visual cues, i.e. } \\
\text { pictures and the cover } \\
\text { of a book to predict what } \\
\text { the story is about } \\
\text { - Identifies key details in } \\
\text { what was read } \\
\text { - Expresses whether } \\
\text { a story was liked } \\
\text { and is able to justify } \\
\text { the response, e.g. 'I } \\
\text { didn't enjoy the story } \\
\text { because...' } \\
\text { - Answers higher order } \\
\text { questions based on the } \\
\text { text read, e.g. 'In your } \\
\text { opinion...' } \\
\text { - Discusses different } \\
\text { cultures represented in } \\
\text { stories } \\
\text { - Interprets pictures and } \\
\text { other print media, e.g. } \\
\text { photographs, calendars, } \\
\text { advertisements, } \\
\text { newspaper and } \\
\text { magazine pictures, } \\
\text { posters }\end{array}$ & $\begin{array}{l}\text { Shared reading as a } \\
\text { class with teacher } \\
\text { - Reads enlarged texts } \\
\text { such as fiction and } \\
\text { non-fiction big books, } \\
\text { newspaper articles, } \\
\text { plays, dialogues } \\
\text { and electronic texts } \\
\text { (computer texts) } \\
\text { - Reads book and } \\
\text { discusses the main } \\
\text { idea, the characters, the } \\
\text { 'problem' in the story, the } \\
\text { plot and the values in } \\
\text { the text } \\
\text { - Answers a range of } \\
\text { higher order questions } \\
\text { based on the passage } \\
\text { read } \\
\text { - Reads different poems } \\
\text { on a topic } \\
\text { - Uses visual cues to talk } \\
\text { about a graphical text, } \\
\text { e.g. advertisements, } \\
\text { pictures, graphs, charts } \\
\text { and maps } \\
\text { • Finds and uses sources } \\
\text { of information, e.g. } \\
\text { community members, } \\
\text { library books } \\
\text { - Uses table of contents, } \\
\text { index and page numbers } \\
\text { to find information } \\
\text { - Uses key words } \\
\text { and headings to find } \\
\text { information in non-fiction } \\
\text { texts } \\
\text { - Uses a dictionary to } \\
\text { find new vocabulary and } \\
\text { their meanings }\end{array}$ \\
\hline
\end{tabular}

(Source: Department of Basic Education 2011: 26) 
The use of pictures to communicate with children not only supports understanding, but can substitute words when needed. According to Guijarro (2013: 345-346), the visual component of communication (or stories) can be used to reflect that which the sender (or author) is not able to express in words. Furthermore, visual components can be used to create narrative tension and emphasise importance as well as create a connection between the characters in the story and the child reader and/or viewer which is not always possible with words alone.

Authors Haust (1989), Guijarro (2011), Ishii (2007), Madigan (2005) and Lester (2006) agree on the importance of visual components for communication with children. Kolucki and Lemish (2011: 27) sum up child-appropriate language, characters and stories by suggesting the use of the following: simple language, descriptive and sensory words, known contexts, repetition and the use of both human and non-human characters. The above suggests that the language used to communicate with foundation phase children must be textually and/or visually suitable, as illustrated in Figure 4.

FIGURE 4: PARTIAL COMMUNICATION MODEL TOWARDS STICKINESS: LANGUAGE

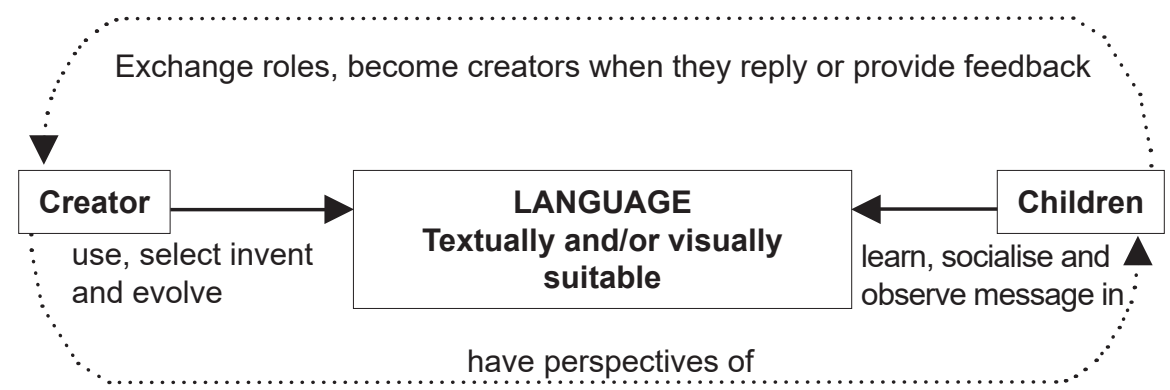

(Source: adapted from Foulger 2004b)

\section{Media requirements of a drought risk reduction message}

Children have access to various communication media including digital, audio and print books, magazines, radio, television, mobile phones, computers, tablets, etc. However, as noted by Kolucki and Lemish (2011: 6), not all children in all areas have access to the different types of media - especially in rural and remote areas children often rely on more traditional media, like print and radio.

Buckingham (2005: 6) points out that access to media has two dimensions. Firstly, it refers to physical access; in other words, do the children for example have access to television, radio, a library or a computer? Secondly, it refers to the ability of the children to actually use the medium, that is, whether they are able to manipulate the technology to receive the message.

With traditional media, access is rarely a problem. Books, for example, can be sent to any location and opening a book is seldom a challenge. Radio and television signals are also quite readily available and the devices fairly easy to operate. Yet, with new 
media, Buckingham's study (2005) found some significant inequalities - the so-called "digital divide" that is closely related to socio-economic status: the less affluent, the less access to modern digital technology.

The current trend with regard to engaging children with content is, however, multiplatform (Thorn 2008: 21). Children's toys and television programmes, for example, are no longer singular items - the same content is presented across various media. Accordingly, a superhero character will be available to children as a toy, movie, television programme, song, storybook, smartphone application, etc. By doing this, content creators attempt to hit as many targets as possible - if a child cannot read, maybe they can play with a toy. If they do not have access to movie theatres, maybe they can get hold of a book or DVD. This approach is not only useful for profitdriven endeavours. Peek (2008: 4) highlights the value of age-appropriate material disseminated through various print and electronic media as a tool to educate children about disasters and engage them in preparedness activities.

The above suggests that the media used to communicate with foundation phase children are required to be both physically and manipulatively accessible, as illustrated in Figure 5.

FIGURE 5: PARTIAL COMMUNICATION MODEL TOWARDS STICKINESS: MEDIA

Exchange roles, become creators when they reply or provide feedback

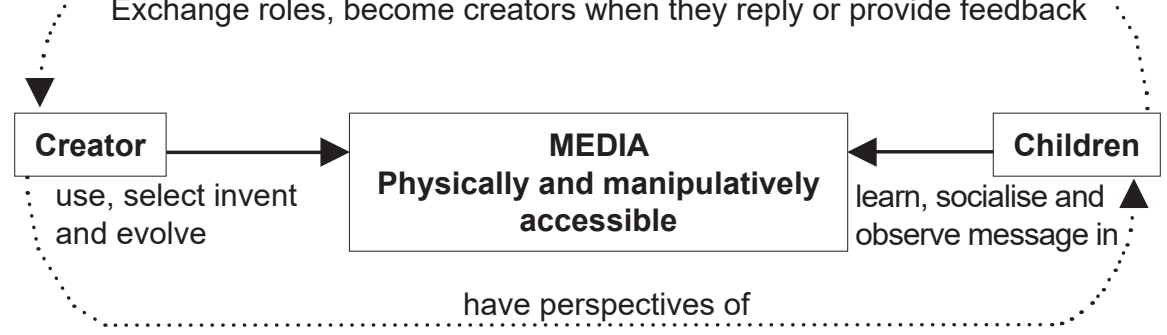

(Source: adapted from Foulger 2004b)

\section{Cultural guidelines for a drought risk reduction message}

Language, knowledge, beliefs, values and attitudes are heavily influenced by culture (Ishii 2007: 18). Cultural differences and subsequent indigenous knowledge and heritage should be taken into account when creating disaster risk reduction messages (Wisner 2006: 84) because cultural differences will also impact on children's knowledge of risk and hazards (Peek 2008: 18). Nonetheless, Lester (2006) asserts that pictures can to a certain extent bridge the gap between cultures to communicate a universal message because they are a globally understood "language".

One should also pay attention to the emergence of a so-called global "children's culture" that groups children from around the world into a like-minded cluster regardless of any regional and/or cultural differences (Buckingham 2005). One of the factors that may 
cause this phenomenon is that although children across the world grow up in diverse cultures, Kolucki and Lemish (2011: 15) note that the developmental stages remain much the same.

One example of this global culture is the distribution of the American children's television programme Sesame Street to more than 150 countries. All co-productions are based on the original template and tailored slightly to suit local conditions. The South African version is called Takalani Sesame. An HIV positive character, Kami, was introduced to address the HIV/Aids issue. The American character Big Bird was replaced by Moishe, who is modelled on a meerkat (Tamagnan, Meredith \& Kato 2015). This confirms the existence of a global children's culture, but also encourages local cultural elements, or that local cultural elements can be enhanced by including global culture elements. Kolucki et al. (2006) reported on a successful educational children's book project in the Kyrgyz Republic, where existing culture and new creations were effectively combined. The books were so popular that they were developed into an animation series.

The above suggests that it is necessary to include both the local and the global children's culture in creating a message for foundation phase children, as illustrated in Figure 6.

FIGURE 6 : PARTIAL COMMUNICATION MODEL TOWARDS STICKINESS: CULTURE

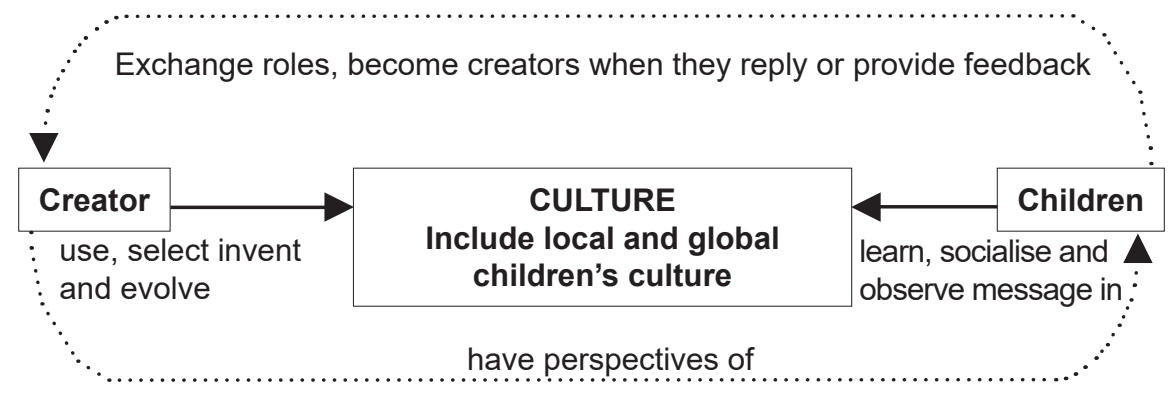

(Source: adapted from Foulger 2004b)

\section{Adapted drought risk reduction communication model for foundation phase children}

When taking all of the above into account, some elaboration and adaptation of Foulger's (2004b) ecological model of the communication process are needed to best communicate a drought risk reduction (DRR) message to foundation phase children. If a message is to be turned into what Gladwell (2013: 89) describes as an "epidemic", like Sesame Street and Blue's Clues, there are three rules to observe: the law of the few, the stickiness factor, and the power or context. The message should be communicated: 
- by an outstanding character (of which there are few)

- in a memorable way (to make the message stick)

- with an understanding of the environment in which the message is received (within a larger culture, there are smaller subgroups that influence the larger group; Gladwell [2013] found that influencing the smaller subgroups often alters the behaviour of the larger group).

The adapted model of Foulger's (2004b) ecological model of the communication process serves as a guide in order to create this so-called stickiness that may cause an educational "epidemic":

\section{FIGURE 7: DRR COMMUNICATION MODEL FOR CHILDREN}

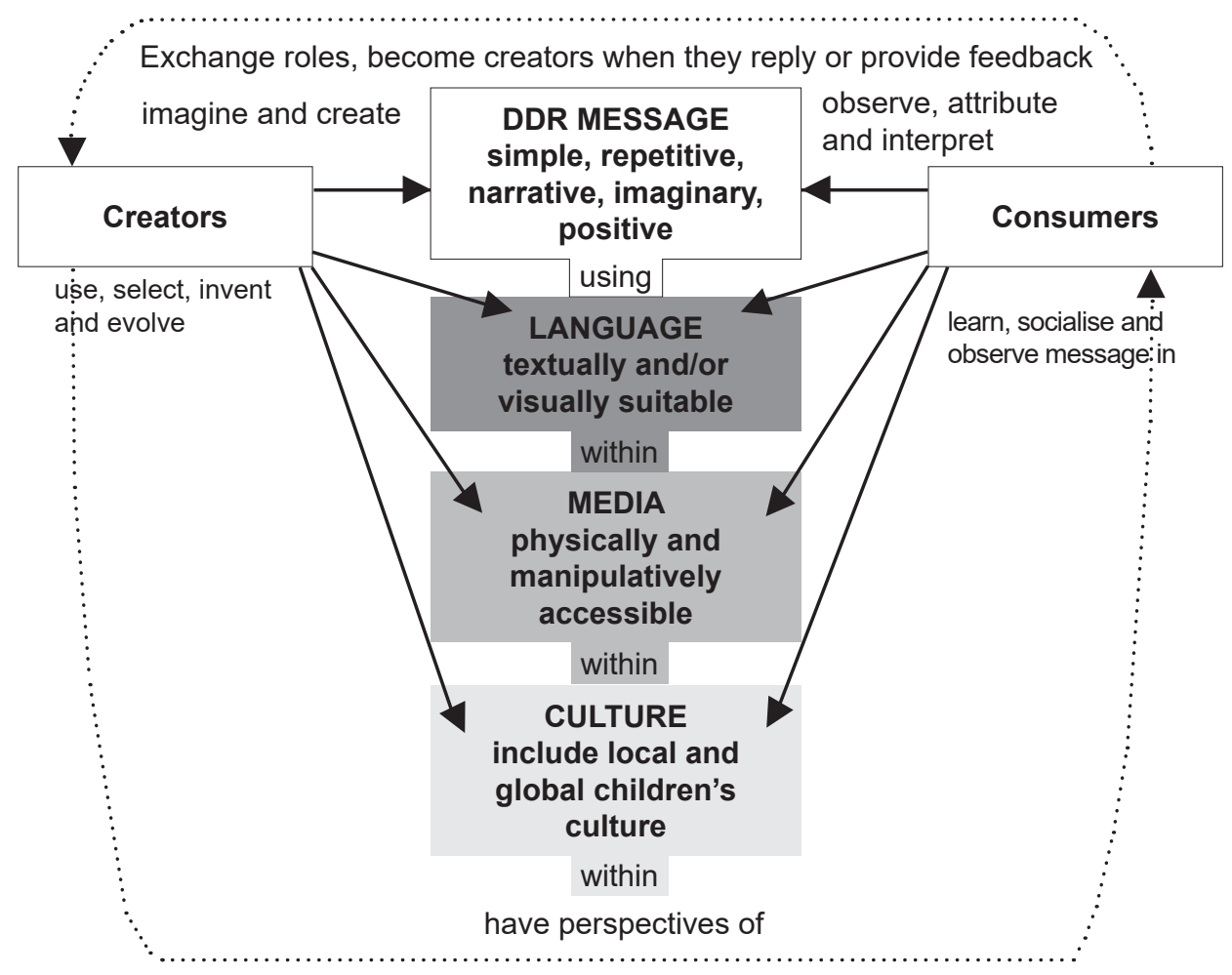

(Source: adapted from Foulger 2004b)

\section{DISCUSSION AND CONCLUSION}

The DRR communication model for children (figure 7) was used as a guide to develop a drought risk reduction message for foundation phase children. Firstly, it was necessary to determine age-appropriate message content for foundation phase children. Much of the drought risk reduction information available is presented as complex data sets or at a level that exceeds the comprehension ability of a foundation phase child. Accordingly, 
the most crucial information was moulded to suit the demands of foundation phase children, as indicated by the DRR communication model for children.

After the message content was determined, it had to be coded into an age-appropriate format. This was done by analysing the preferred coding options for foundation phase children. It soon became apparent that words alone would not suffice - the larger part of a foundation phase child's understanding depends on visual stimuli. Therefore, the textual and the visual coding needed to be used in unison and as per age-appropriate requirements.

Once the message is coded, it must be sent via the most suitable communication channel. As suggested by the DRR communication model for children, it must be physically and manipulatively accessibly - the study discussed in this article found that a picture book is the most appropriate channel for foundation phase children. Local and global cultural needs were also taken into account before the message was finalised and packaged.

It was found that the message developed according to the guidelines of the DRR communication model for children did indeed stick, that is, foundation phase children paid attention to the message, understood it and remembered it well enough to engage in a discussion about it. Five observations with a total of 33 foundation phase children were conducted. It was also found that the children remembered the message up to seven months after the initial exposure.

The limitations of the study included the ever-changing global children's landscape. However, the model allows room for adaptation in recognising both the local and the global children's culture in message development. And, although great care was taken to adhere to scientific objectivity in preparing the message, constructing the data collection tool, and during analysis, potential research bias is a possibility.

This DRR communication model for children allows opportunities for further research in that it can be used to develop and test other types of messages. Furthermore, the impact of each component of the model (message, language, media, and culture) can be researched in order to determine the weight it carries in message creation.

\section{REFERENCES}

Arab-Moghaddam, N. \& Sénéchal, M. 2001. Orthographicand phonological processing skills in reading and spelling in Persian/English bilinguals. International Journal of Behavioural Development 25(2): 140-147. http://dx.doi.org/10.1080/01650250042000320

Blackburn, P.L. 2007. The code model of communication: A powerful metaphor in linguistic metatheory. SIL International.

Buckingham, D. 2005. The media literacy of children and young people. A review of the research literature on behalf of Ofcom. Centre for the Study of Children, Youth and Media, Institute of Education. University of London: London. [Online]. Available at: http://eprints.ioe.ac.uk/145/1/Buckinghammedialiteracy.pdf [Accessed on 1 May 2014]. 
Clerveaux, V., Spence, B. \& Katada, T. 2010. Promoting disaster awareness in multicultural societies: The DAG approach. Disaster Prevention and Management 19(2): 199-218. http://dx.doi.org/10.1108/09653561011038002

Cohen, L., Manion, L. \& Morrison, K. 2007. Research methods in education. (Sixth edition). London: Routledge.

Corman, S.R., Trethewey, A. \& Goodall, B. 2007. A $21^{\text {st }}$ century model of communication in the global war of ideas. From simplistic influence to pragmatic complexity. Consortium for Strategic Communication. US: Arizona State University.

Department of Basic Education. 2011. Curriculum and Assessment Policy Statement Grades R3 English Home Language. Pretoria: Government Printing Works.

Department of Basic Education. 2014a. Grade 3 English Home Language Book 1. Pretoria: Government Printing Works.

Department of Basic Education. 2014b. Grade 3 English Home Language Book 2. Pretoria: Government Printing Works.

Dolch Word List. 2014. Complete Dolch Word List. [Online]. Available at: http://www. bogglesworldesl.com/dolch/sightwords.htm [Accessed on 6 May 2014].

Figueroa, M.E., Kincaid, D.L., Rani, M. \& Lewis, G. 2002. Communication for social change: An integrated model for measuring the process and its outcomes. New York: The Rockefeller Foundation.

Foulger, D.A. 2004a. Models of the communication process. Evolutionary Media: Brooklyn. [Online]. Available at: http://davis.foulger.info/research/unifiedModelOfCommunication. $\mathrm{htm}$ [Accessed on 15 September 2013].

Foulger, D.A. 2004b. An ecological model of the communication process. [Online]. Available at: http://davis.foulger.info/papers/ecologicalModelOfCommunication.htm [Accessed on 30 March 2014].

Fry Words. 2010. Fry 1000 Instant Words. [Online]. Available at: http://www.uniqueteachingresources.com/Fry-1000-Instant-Word.html [Accessed on 6 May 2014].

Gladwell, M. 2013. The tipping point. London: Abacus.

Guijarro, A.J.M. 2011. Engaging readers through language and pictures. A case study. Journal of Pragmatics 43: 2982-2991. http://dx.doi.org/10.1016/j.pragma.2011.05.012

Guijarro, A.J.M. 2013. Visual metonymy in children's picture books. Review of Cognitive Linguistics 12(2): 336-352.

Hamilton, M. \& Weiss, M. 2005. Children tell stories: Teaching and using storytelling in the classroom. (Second edition). New York: Richard C. Owen.

Haust, W. 1989. Writing for visual communication. Writing Across the Curriculum 1(1): 23-27.

Holmes, D. 2005. Communication theory. Media, technology, society. London: Sage.

Ishii, M. 2007. Children communicating visually through photographs. Unpublished Master's dissertation. Hawaii: University of Hawaii.

Jongejan, W., Verhoeven, L. \& Siegel, L.S. 2007. Predictors of reading and spelling abilities in first - and second-language learners. Journal of Educational Psychology 99(4): 835-851. http://dx.doi.org/10.1037/0022-0663.99.4.835 
Jorgensen, D.L. 1989. Participant observation. California: Sage. http://dx.doi.org/10.4135/ 9781412985376

Kirkorian, H.L., Wartella, E.A. \& Anderson, D.R. 2008. Media and young children's learning. The Future of Children 18(1): 39-61. http://dx.doi.org/10.1353/foc.0.0002

Kolucki, B., Iskanderova, A. \& Grover, D. 2006. Something to read, something to learn. Print media for and about children. Kyrgyz Republic: UNICEF.

Kolucki, B. \& Lemish, D. 2011. Communicating with children: Principles and practices to nurture, inspire, excite, educate and heal. New York: UNICEF.

Lester, M.L. 2006. Syntactic theory of visual communication. Department of Communications, California State University: California. [Online]. Available at: http://commfaculty. fullerton.edu/lester/writings/viscomtheory.html [Accessed on 28 April 2014].

Lipka, O. \& Siegel, L.S. 2007. The development of reading skills in children with English as a second language. Scientific Studies of Reading 11(2): 105-131. http://dx.doi. org/10.1080/10888430709336555

Littlejohn, S.W. \& Foss, K. 2009. Encyclopaedia of communication theory. California: Sage http://dx.doi.org/10.4135/9781412959384

Madigan, S. 2005. Using symbol communication to support pre-school children with English as an additional language. Childhood Research Unit Institute of Education, University of Warwick: UK. [Online]. Available at: http://www.ness.bbk.ac.uk/ support/ local-evaluation-findings/documents/1324.pdf [Accessed on 1 May 2014].

Miller, A.C. \& Keenan, J.M. 2009. How word decoding skill impacts text memory: The centrality deficit and how domain knowledge can compensate. Annals of Dyslexia 59: 99-113. http://dx.doi.org/10.1007/s11881-009-0025-x

Miller, C.R. 1996. Communication in the $21^{\text {st }}$ century: The original liberal art in an age of science and technology. North Carolina: North Carolina State University Publication Series.

Miller-Day, M., Pezella, A. \& Chesnut, R. 2013. Children are in families too! The presence of children in communication research. Journal of Family Communication 2013(13): 150-165. http://dx.doi.org/10.1080/15267431.2013.768251

Nakayama, M., Sears, C.R. \& Lupker, S.J. 2010. Testing for lexical competition during reading: Fast priming with orthographic neighbors. Journal of Experimental Psychology: Human Perception and Performance 36(2): 447-492. http://dx.doi. org/10.1037/a0016800

Patton, M.Q. 2001. Qualitative research \& evaluation methods. (Third edition). California: Sage.

Peek, L. 2008. Children and disasters: Understanding vulnerability, developing capacities, and promoting resilience - An introduction. Children, Youth and Environments 18(1): 1-29.

Perkins, J. 1998. Dolch Words. [Online]. Available at: http//:www.mrsperkins. com/files/ dolch_book.pdf [Accessed on 6 May 2014].

Pretorius, E.J. \& Machet, M.P. 2004. The socio-educational context of literacy accomplishment in disadvantaged schools: Lessons for reading in the early primary school years. Journal for Language Teaching 38(1): 45-62. http://dx.doi.org/10.4314/jtt.v38i1.6027 
Rambau, S.T. 2011. Educational perspectives on learner awareness of hazards and disasters. Unpublished doctoral thesis. University of Pretoria, South Africa.

Rasinski, T.V. 2003. The fluent reader. New York: Scholastic.

Rvachew, S. \& Bernhardt, B.M. 2010. Clinical implications of dynamic systems theory for phonological development. American Journal of Speech-Language Pathology 19: 34-50. http://dx.doi.org/10.1044/1058-0360(2009/08-0047)

Shaw, R., Shiwaku, K., Kobayashi, H. \& Kobayashi, M. 2004. Linking experience, education, perception and earthquake preparedness. Disaster Prevention and Management 13(1): 33-49. http://dx.doi.org/10.1108/09653560410521689

Shiwaku, K., Shaw, R., Kandel, C., Shrestha, S. \& Dixit, A. 2007. Future perspective of school disaster education in Nepal. Disaster Prevention and Management 16(4): 576-587. http://dx.doi.org/10.1108/09653560710817057

Tamagnan, M., Meredith, B. \& Kato, R. 2015. A case study of the Takalani Sesame program in South Africa. [Online]. Available at: https://wiki.harvard.edu/confluence/ download/ attachments/159810316/Kato_Meredith_Tamagnan_Takalani\%20Sesame $\% 20$ Case $\% 20$ Study.pdf? version $=1 \&$ modificationDate $=1421421026000 \&$ ap $=v 2$ [Accessed on 3 September 2015].

Thorn, W.J. 2008. Preschool children and the media. Communication Research Trend 27: 1-43.

UNICEF. 2006. Programme development for early childhood development. New York: UNICEF.

Wilhite, D.A. 1999. Drought preparedness in the Sub-Saharan African context. International Conference on Integrated Drought Management, Pretoria.

Wisner, B. 2006. A review of the role of education and knowledge in disaster risk reduction. India: Books for Change. 